\title{
Science policy in the developing world Ziauddin Sardar
}

Science, Technology and Development: Essays in Honour of A. Rahman. Edited by K.D. Sharma and M.A. Qureshi. Pp. 478. (Sterling Publishers: New Delhi, 1978.) Rs 120.

THIS anthology of papers on the themes of science policy, science and society, technology assessment, technology and underdevelopment, research management and science in India is a fitting tribute to Professor A. Rahman, "whose pioneering work", in the words of J. J. Soloman, "in science policy studies related to the problems of development has been outstanding". The idea of honouring a Third World scientist who has made a varied and sustained contribution to knowledge is indeed appropriate and thee must certainly be others who would have liked to be associated with it.

Science, Technology and Development opens with a brief biographical sketch of A. Rahman. Rahman was educated at the Aligorh Muslim University and in England where he studied biochemistry under the Noble Laureate H.A. Cripps and came in contact with such scholars of the left as J.D. Bernal, Joseph Needham, J.B.S. Haldane and H. Levy. Their influence has obviously left its mark on his thinking and is responsible for his switch from biochemistry to the history and social philosophy of science. Rahman's distinguished career in the Council of Scientific and Industrial Research (CSIR) began at Regional Research Laboratory in Hyderabad immediately after his return from England. Since then he has served in many CSIR laboratories, moving, in 1963, to CSIR Headquarters in New Delhi to organise an information centre and to develop a systems approach to planning and resource allocation for the various laboratories of CSIR. Currently, he is Chief of Planning at CSIR and leads the Centre for the Study of Science, Technology and Development.

There are 26 papers in this presentation volume, inevitably of uneven quality. Some of the essays (for example, J. J. Soloman on "Science Policy and Social Objectives", E. B. Skolnik off on "The Governability of Complexity", A.
H. Rubenstein, T. W. Schlie and A. D. Jedlicka on "Some Current Field of Research on "Appropriate Technologies for the Less Developed Countries" and S. R. Mikulinsky on "The Present State and Problems of the History of Natural Science") seem to be positively dated, some others (for example, Y. de Hemptine on "Integrated versus Sectoral Policies for Science and Technology", Jozef Bognar on "Culture, Science and Economy" and D. de Solla Price on "India as a Small Highly Developed Scientific Nation") are in the nature of fragments only; but, on the whole, there is enough thought provoking material here for the volume to be valuable to both the students and researchers of the social relations of science and technology.

The volume is at its strongest when dealing with science and technological policy in India. In a commanding analysis, A. K. N. Reddkly argues for the generation of environmentally sound and appropriate technolgies for rural development. His strategy is based on two. components: forging strong links between the educational, scientific and technological institutions and the needs of the rural poor and their traditional technologies, on the one hand, and drastically weakening the reliance of these institutions on elitist demands and on institutions in the developed world. A strategy after my own heart, and one that C. Subramaniam shows so convincingly is bound to be fruitful.

Subramaniam describes a rural strategy developed for Karimnager, "a backward district of Andhra Pradesh". The work in Karimnager began with an assessment of soil, geohydrological and forest resources, an assessment of human potential, identification of new irrigation wells and a determination of fertilizer doses, and proceed to the planning of feeder roads and housing colonies based on techniques that emphasise maximum use of local material and skills. A windmill was designed and built for lifting water from the only source of drinking water in the village, carried out with the help of the National Aeronautical Laboratory, "which till then used to interest itself in nothing less lowly than designing and testing aeronautical systems for jet aircrafts". Other projects developed for Karimnager included the collections of all waste material - human, animal and agricultural - to be processed in an inexpensive biogas plant to produce domestic fuel and fertiliser, the substitution of rubber-roller type of shellers for the more conventional energy: sheller in rice processing equipment, and improvement of various techniques from bee-keeping, making palm-candy to tanning and securing a better extraction of fibre from banana and sisal. Karimnager, K. Subramaniam argues forcefully, is a shining example of what can be achieved when scientists turn their attention to the needs of the rural poor.

India is saturated with Karimnagers and it is reasonable to assume that this success story will be repeated elsewhere. Indeed, as K. D. Sharma and M. A. Qureshi argue in their contribution, "A Framework for Alternative Technology", India needs to develop a mix of "traditional small and big technologies to achieve composite development so as to strike a balance between the internal socio-economic situation and external plolitical stability". Although "national prestige" and "national security" figure large in their thinking, Sharma and Qureshi are really arguing for an upgrading of traditional technologies and a little more scrutiny of high technology projects. There is little doubt that India cannot tolerate, as Ward Morehouse shows in his richly detailed study of "Scuttling the Coal Gasification Project at Hyderabad: The Perils of Public Patronage in Bridging the Development Gap", a situation where its science is unwittingly pushed forward in large, prestigous undertakings. Scientists like Rahman, who turn their attention from the glare of prestige science and high technology to the plight of the rural poor and the real issues of development, deserve commendation from all who put people before glory.

Ziauddin Sardar is an Information Consultant to the Hajj Research Centre, King Abdul Aziz University, Jeddah, Saudi Arabia. 